\title{
Research on Instantaneous Power Control Strategy for PWM Rectifier
}

\author{
Yanping Zhong and Yaojun Chen \\ Air Force Early Warning Academy, Wuhan, China
}

\begin{abstract}
The voltage and current double closed-loop control strategy is usually used in three-phase voltage-source PWM rectifier control. However the nonlinear characteristic of the voltage equation gives more trouble to design this control strategy. A comparative study of two kinds of linear instantaneous power control strategies for PWM rectifier is presented, who are that only using a linear PI regulator and that using a PI regulator with load power feed-forward. It is pointed out that the system response can greatly be faster by using the load power feed-forward contro1. On this basis, according to the nonlinear characteristic of voltage equation, the control strategy based on load power feed-forward control is modified, which not only inherits the advantages of the fast response of the control strategy, but also realizes the linear control of the output voltage. MATLAB simulation and experimental results indicate the validity of the control strategy.
\end{abstract}

Keywords-rectifier; nonlinear; instantaneous power control; pulse width modulation

\section{INTRODUCTION}

With the development of power electronic technology, the three phase voltage-source PWM rectifier is widely used. The voltage and current dual closed-loops control and space vector modulation are usually used for the three-phase voltage-source PWM rectifier. Linear PI control is usually used for voltage loop ${ }^{[1]}$, and decoupling control is used in current loop ${ }^{[2,3]}$. However, because of the nonlinear characteristic of the balance equation of output voltage, linear PI control can not solve this nonlinear problem apparently. Meanwhile, the system performance will become worse and even become unbalance anymore with the linear PI control. A nonlinear control strategy based on linear state-feedback is proposed in [1], however, its algorithm is complicated and it is sensible to the parameters' variation.

On the other hand, because of the nonlinear characteristic of the balance equation of output voltage, the system analysis is difficult. Therefore, the instantaneous power model is established in this paper. Two kinds of linear control strategy are researched comparatively, which proves the linear relation between the voltage error and the output power with linear control strategy. After its modification, the advantage of control strategy based on load power feed-forward is reserved; the linear control of output voltage is realized while the response rapidity of current is faster than output voltage. It is visible that this strategy is not only an instantaneous power control but also a nonlinear control of output voltage. Simulation and experimental results indicate its validity.

\section{MATH MODEL OF PWM RECTIFIER}

\section{A. Selecting a Template}

The topology of three-phase voltage source PWM rectifier is shown in Figure1. IGBT and diode are anti-paralleled in the main circuit, $L_{s}$ is filter and energy-regulation inductance, and $R_{s}$ is system equivalent resistance.

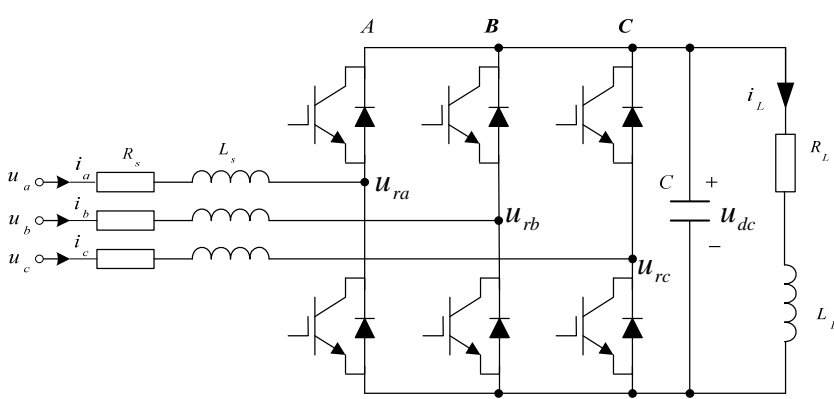

FIGURE I. THREE-PHASE VOLTAGE SOURCE PWM RECTIFIER

From Figure 1, equation of PWM rectifier in synchronous rotating dq coordinates is given as follows:

$$
\begin{aligned}
& \left\{\begin{array}{l}
u_{r d}=-L_{s} \frac{d i_{d}}{d t}-R_{s} i_{d}+\omega L_{s} i_{q}+u_{s d} \\
u_{r q}=-L_{s} \frac{d i_{d}}{d t}-R_{s} i_{d}-\omega L_{s} i_{d}+u_{s q} \\
C \frac{d u_{d c}}{d t}=\frac{3}{2}\left(S_{d} i_{d}+S_{q} i_{q}\right)-i_{L}
\end{array}\right. \\
& P_{i n}=\frac{3}{2}\left(u_{s d} i_{s d}+u_{s q} i_{s q}\right)=u_{d c} C \frac{d u_{d c}}{d t}+u_{d c} i_{L}
\end{aligned}
$$

where $u_{s d}, u_{s q}$ are $\mathrm{d}$ and q components of input voltage, $i_{s d}$, $i_{s q}$ are $\mathrm{d}$ and q components of input current, $S_{d}, S_{q}$ are $\mathrm{d}$ and q components of switch function.

To balanced three-phase system, $u_{s d}=E_{m}, u_{s q}=0$, where $E_{m}$ is the peak value of input phase voltage. 


\section{MODEL OF INPUT AND OUTPUT POWER}

\section{A. Response of Input Power}

From (1), there exist coupling between $i_{d}$ and $i_{q}$, so current state feedback decoupling control or current error feed-forward decoupling can be used. If the decoupling is completed, the current control system can be equivalent to first-order system, and its closed-loop transfer function is obtained as:

$$
\frac{I_{d}(s)}{I_{d}^{*}(s)}=\frac{1}{1+T_{i f} s}, \frac{I_{q}(s)}{I_{q}^{*}(s)}=\frac{1}{1+T_{i f} s}
$$

where $T_{\text {if }}$ is time constant of current response.

Active current $i_{d}{ }^{*}$ and reactive current $i_{q}^{*}$ are expressed as:

$$
\left[\begin{array}{c}
i_{d}^{*} \\
i_{q}^{*}
\end{array}\right]=\left[\begin{array}{c}
\frac{2 P_{i n}^{*}}{3 E_{m}} \\
0
\end{array}\right]
$$

From (2) and (3), we obtain

$$
P_{i n}(s)=\frac{1}{1+T_{i f} s} \cdot \frac{3}{2}\left(u_{s d} i_{d}^{*}(s)+u_{s q} i_{q}^{*}(s)\right)=\frac{1}{1+T_{i f} s} P_{i n}^{*}(5)
$$

\section{B. Model of DC-Side Capacitor Power}

The DC-side capacitor is used to balance the output voltage and eliminate the voltage harmonics. Capacitor power $P_{C}$ is the error between input power $P_{\text {in }}$ and load power $P_{L}$, that is $P_{C}=P_{L}-P_{i n}$. Based on the physical characteristic of capacitor, we get

$$
C \frac{u_{d c}^{2}(0)-u_{d c}^{2}(t)}{2}=\int_{0}^{t} P_{C}(t) d t
$$

where: $u_{d c}(t)$ is voltage variable, $u_{d c}(0)$ is the initial voltage value of capacitor, $u_{d c}(0)=u_{d c}^{*}, u_{d c}^{*}$ is the voltage value of steady state.

Let $e_{d c}(t) \equiv u_{d c}(0)-u_{d c}(t)$, square both sides and based on $u_{d c}^{*}>>e_{d c}$, neglecting the small components, we obtain

$$
u_{d c}^{2}(t) \cong u_{d c}^{* 2}-2 u_{d c}^{*} e_{d c}(t)
$$

From (6) and (7), we get

$$
e_{d c}(t)=\frac{1}{C u_{d c}^{*}} \int_{0}^{t} P_{C}(t) d t
$$

Using Laplace's equation, (8) is transferred into

$$
\frac{e_{d c}(s)}{P_{C}(s)}=\frac{1}{s C u_{d c}^{*}}
$$

\section{InStANTANEOUS POWER CONTROL STRATEGY}

\section{A. Linear Control Strategy}

Based on analysis above, closed-loop structure of instantaneous power control is shown in Fig.2. If let $v=\left(K_{P u}+K_{I u} / s\right) e_{d c}$, where $K_{P u}, K_{I u}$ are the proportion and integral parameters, then there are two kinds of control method according to the different definition of $P_{C}^{*}$ and $P_{L}^{*}$.

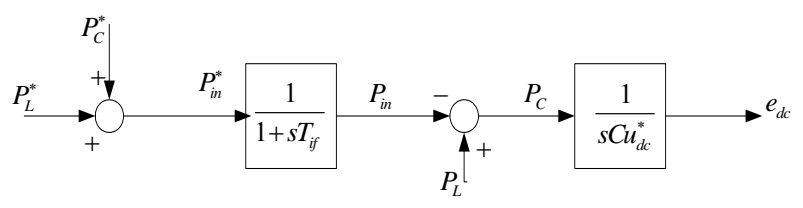

FIGURE II. FLOW OF SYSTEM POWER CONTROL

(1) Case 1: Defining $P_{C}^{*}=v, P_{L}^{*}=0$, the transfer function between $e_{d c}(s)$ and $P_{L}(s)$ is expressed as following:

$$
\frac{e_{d c}(s)}{P_{L}(s)}=\frac{\left(1+T_{i f} s\right) s}{u_{d c}^{*} T_{i f} C s^{3}+u_{d c}^{*} C s^{2}+K_{P u} s+K_{I u}}
$$

(2) Case 2: Defining $P_{C}^{*}=v, P_{L}^{*}=P_{L}$, the transfer function between $e_{d c}(s)$ and $P_{L}(s)$ is expressed as following:

$$
\frac{e_{d c}(s)}{P_{L}(s)}=\frac{s^{2}}{u_{d c}^{*} T_{i f} C s^{3}+u_{d c}^{*} C s^{2}+K_{P u} s+K_{I u}}
$$

According to the linear relation between voltage error and load power, compared with case 1, load power feed-forward control is applied in case 2. The bode map of (10) and (11) are shown in Figure 3. $T_{i f}=2 \mathrm{~ms}, u_{d c}^{*}=600 \mathrm{~V}$, $C=0.0032 F, K_{P u}=1 \mathrm{~W} / \mathrm{V}, K_{I u}=5 \mathrm{~W} / \mathrm{V}$.

Figure 3 illustrates that (11) has a smaller plus and faster response rapid, when there is load power disturbance. It indicates that system response rapid is accelerated after 
inducting load power feed-forward control.

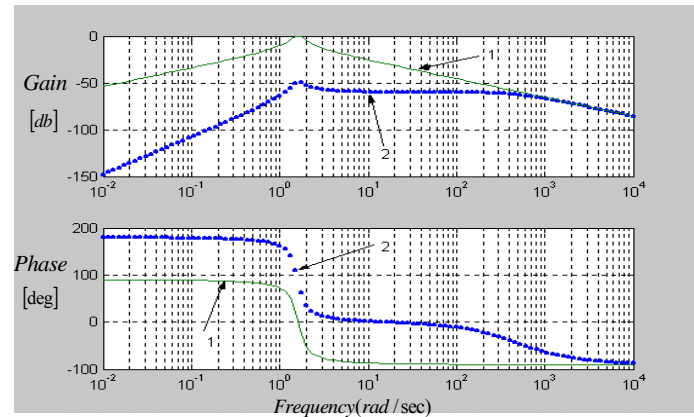

FIGURE III. BODE MAPS OF TRANSFER FUNCTION OF CASES

\section{B. Nonlinear Control Strategy}

The system uses double closed loops control, assuming the response rapid of current inside-loop is greatly faster than voltage outside-loop, so the time constant of current loop is neglected when discussing the control of voltage loop. Then $P_{\text {in }}^{*} \cong P_{i n}$, and $v=u_{d c} C d u_{d c} / d t$ according to case 2 .

Apparently, the control of voltage is nonlinear, so although the system response rapid is accelerated by using case 2 , it doesn't change the nonlinear characteristic of output voltage. If we give linearization to it, the system will be steady, but system will be affected by nonlinear characteristic. But if we define $P_{C}^{*}=u_{d c} v$, then $v=C d u_{d c} / d t$.

Therefore, the closed-loop transfer function of output voltage is obtained as:

$$
\frac{u_{d c}(s)}{u_{d c}^{*}(s)}=\frac{K_{P u}\left(s+K_{I u}\right)}{C\left(s^{2}+\frac{K_{P u}}{C} s+\frac{K_{P u} K_{I u}}{C}\right)}
$$

From (12), the system is second-order system. We define it as case 3. assuming output voltage is unchanged under small signal model condition, according to case 3 , the transfer function between $e_{d c}(s)$ and $P_{L}(s)$ is expressed as following:

$$
\frac{e_{d c}(s)}{P_{L}(s)}=\frac{s^{2}}{u_{d c}^{*} T_{i f} C s^{3}+u_{d c}^{*} C s^{2}+u_{d c} K_{P u} s+u_{d c} K_{I u}}
$$

Comparing (11) with (13), their structures are the same basically, so in the perspective of power control, there is no difference between case 2 and 3. However, case 2 only realizes the linearization of input power and the control of output voltage is still nonlinear. Case 3 realizes the linear control of output voltage.

\section{SimULATION AND EXPERIMENTAL RESUlTS}

According to Figure 4, the control of PWM rectifier is simulated by MATLAB 6.0. Simulation parameters are given as follows: input three-phase $\mathrm{AC}$ voltage $220 \mathrm{~V} / 50 \mathrm{~Hz}$, $R_{S}=0.002 \Omega, L_{S}=10 \mathrm{mH}, u_{d c}^{*}=600 \mathrm{~V}, I_{q}^{*}=0, \mathrm{C}=3250 \mu \mathrm{F}$, the proportion and integral parameters of current regulator are $K_{P i}=20, K_{I i}=50, K_{P u}=1, K_{I u}=10, K_{P L}=5, K_{I L}=10, L_{L}=0$, when $\mathrm{t}<3 \mathrm{~s}, R_{L}=0$, when $3 \mathrm{~s} \leq t<3.2 \mathrm{~s}, R_{L}=50 \Omega$, when $t \geq 3.2 \mathrm{~s}, R_{L}=-50 \Omega$. When $R_{L}>0$, output current is positive and rectifier works as a rectifier, when $R_{L}<0$, output current is negative and rectifier works as an inverter.

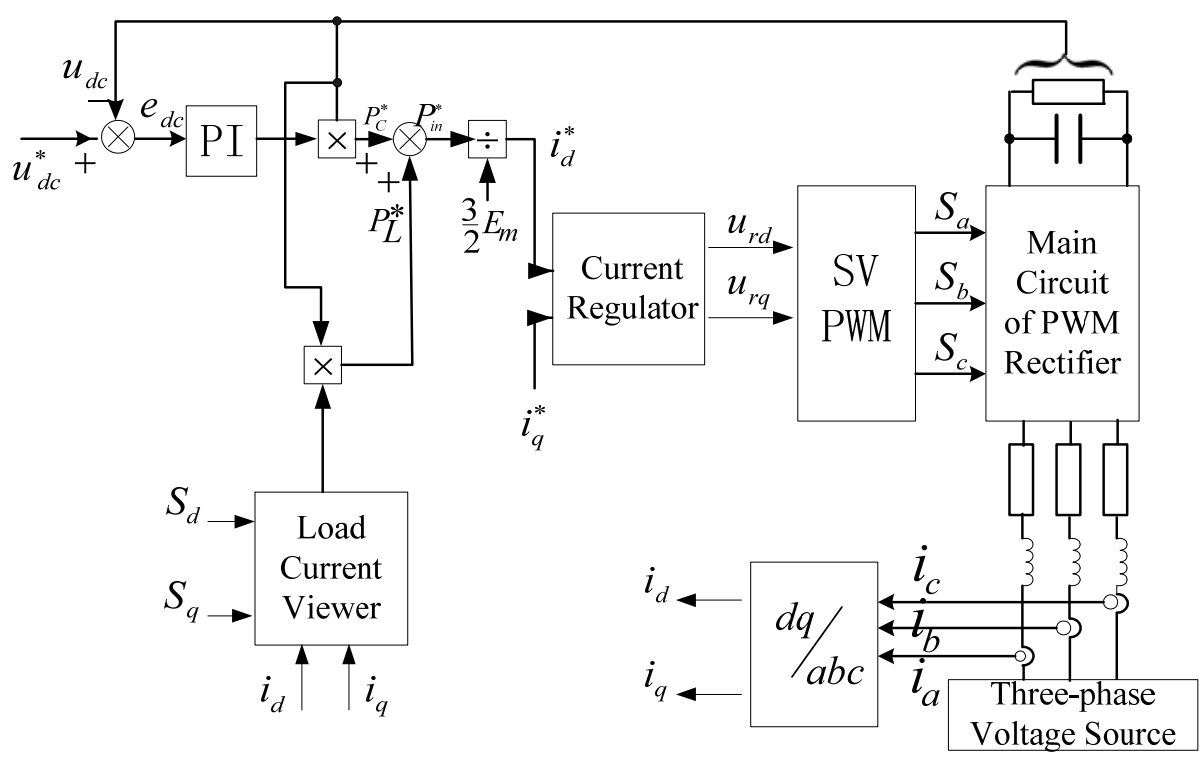

FIGURE IV. CONTROL STRUCTURE OF SYSTEM 
Figure 5 shows the waveform of output voltage using case 1, 2 and 3. Case 2 and 3 have smaller over-load and faster response rapid. When rectifier works as a rectifier, case 3 and 2 have the same performance. When rectifier works as an inverter, case 3 is better than case 2 . The result shows that case 3 is a nonlinear control of output voltage essentially and it has a wider working range than case 2 .

Figure 6 shows the experimental waveforms of output voltage of different cases. Experimental parameters are the same as simulation parameters. When rectifier works as a rectifier with no load, we add load suddenly, the output power is $5 \mathrm{KW}$.

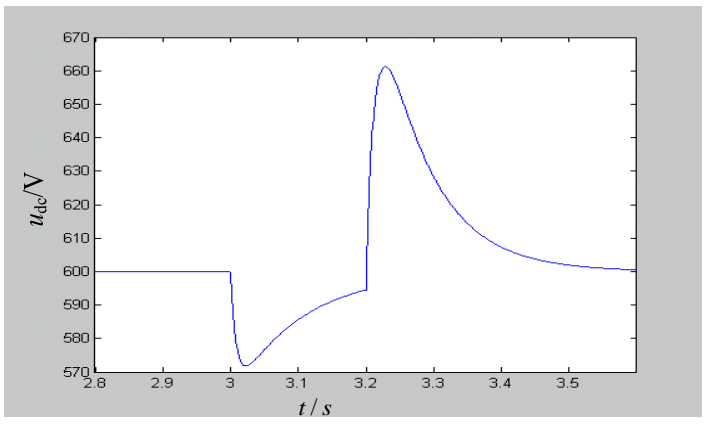

(A) CASE 1

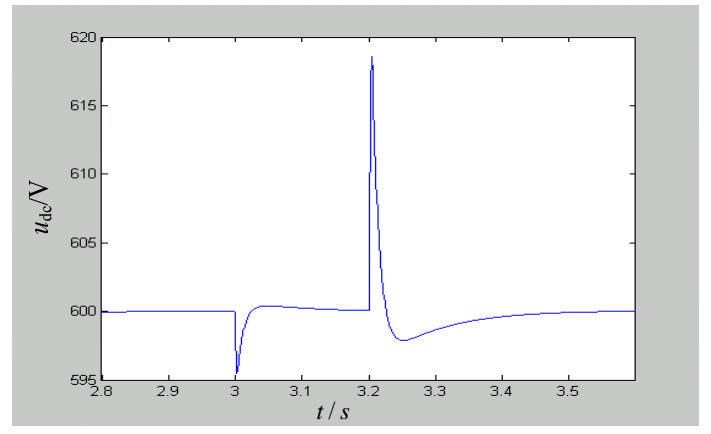

(B) CASE 2

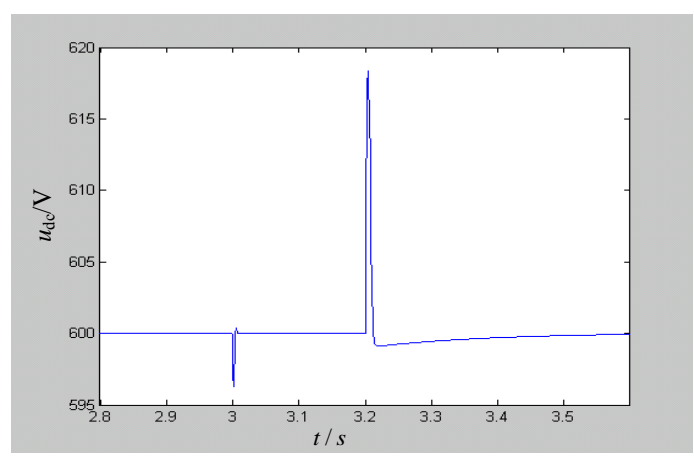

(C) CASE 3

FIGURE V. THE OUTPUT VOLTAGE SIMULATION WAVES WITH DIFFERENT STRATEGIES

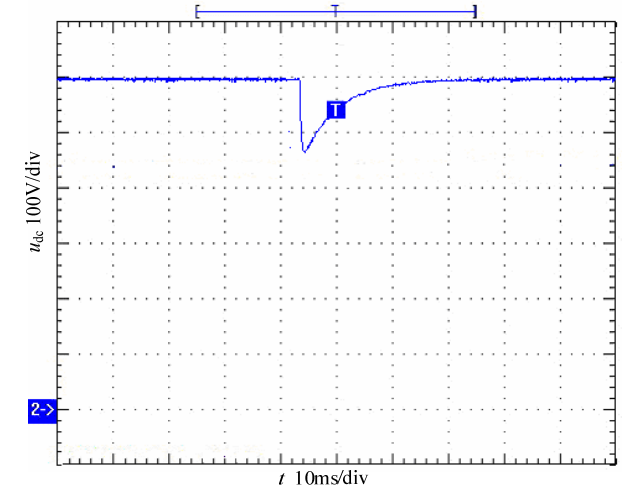

(A) CASE 1

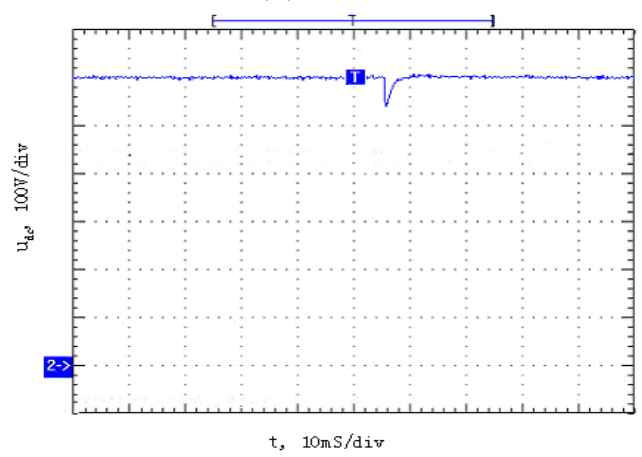

(B) CASE 2, 3

FIGURE VI. THE OUTPUT VOLTAGE EXPERIMENT WAVES WITH DIFFERENT STRATEGIES DIFFERENT STRATEGIES

\section{CONCLUSION}

This paper analyzed the control strategy of PWM rectifier in the prospective of power flow. Two kinds of linear control method were compared. It was illustrated that control strategy based on load power feed-forward control has a faster response rapid. There is a linear relation between voltage error and power; however the control of output voltage is nonlinear. Then the control strategy based on load power feed-forward control was modified, which inherits the advantages of the control strategy and realized the linearization of output voltage contro1. The simulation and experimental results indicated the validity of the control strategy.

\section{REFERENCES}

[1] Dong-Choon Lee G-Myoung Lee, and Ki-Do Lee. DC-Bus Voltage Control of Three-Phase AC/DC PWM Converters Using Feedback Linearization [J]. IEEEE Trans. on industry Applications, 2000, 36(3): 826-833.

[2] Yaojun Chen, Yanping Zhong. Study on the Current Control for Voltage-Source PWM Rectifier Using Complex Vectors [J]. Proceedings of the CSEE, 2006, 26(2): 143-148.

[3] Yanping Zhong, Songhua Shen. Decoupled Control and DSP implement of PWM Rectifier [A]. Proceedings of the 5th World Congress on Intelligent Control and Automation[C]. Hang-Zhou, China, June, 2004.9: 5199-5202. 